\title{
Isopropylation of benzene with 2-propanol over substituted large pore aluminophosphate-based molecular sieves
}

\author{
K JOSEPH ANTONY RAJ and V R VIJAYARAGHAVAN* \\ Department of Physical Chemistry, School of Chemical Sciences, University of Madras, Guindy Campus, \\ Chennai 600 025, India \\ e-mail: kjoseph_antony@yahoo.com; vijju@vsnl.com
}

MS received 14 July 2003; revised 10 November 2003

\begin{abstract}
Large pore aluminophosphate-based molecular sieves like $\mathrm{AlPO}_{4}-5$, MAPO-5, MnAPO-5 and ZAPO-5 were synthesised hydrothermally using triethylamine as a structure directing agent. These materials were characterised by X-ray diffraction (XRD), ${ }^{27} \mathrm{Al}$ and ${ }^{31} \mathrm{P}$ MAS-NMR, ICP-MS, $n$-butylamineTPD, BET and SEM. The catalytic performance of these materials was tested for isopropylation of benzene with 2-propanol at $250,300,350$ and $400^{\circ} \mathrm{C}$. The products were cumene, $p$-DIPB ( $p$-diisopropylbenzene) and $m$-DIPB ( $m$-diisopropylbenzene). MnAPO-5 was found to be more active than the other catalysts. Maximum conversion $(20 \%)$ was noted at $350^{\circ} \mathrm{C}$ over MnAPO-5. The selectivity to DIPB was found to decrease with time on stream but the selectivity to cumene showed an increase after $3 \mathrm{~h}$ of time on stream.
\end{abstract}

Keywords. Aluminophosphate; AlPOs; benzene; cumene; isopropylation; molecular sieves.

\section{Introduction}

Alkylation of benzene with propylene to produce cumene is a well-known reaction. Cumene is an important chemical intermediate mainly used for the production of phenol and acetone. ${ }^{1}$ Cumene production is one of the potential routes for manufacturing $m$-DIPB and $p$-DIPB isomers, two important intermediates for polymer industries. In the petrochemical industry, phosphoric acid is the catalyst used for benzene alkylation. ${ }^{2} \mathrm{AlCl}_{3}$ has also been used as a catalyst for benzene alkylation. ${ }^{3}$ The major drawback of these catalysts is their corrosive and environmentally hazardous nature. To overcome these problems, commercial cumene processes, catalysed by zeolites, have been developed by Mobil and CDTECH. ${ }^{4,5}$ Other zeolites have also been tested for alkylation of benzene with propylene and/or 2-propanol. ${ }^{6,7}$ Although isopropylation of benzene has been largely studied over zeolites, studies with zeotype molecular sieves are scarce. Aluminophosphate molecular sieves are microporous solids that find a wide range of applications in the catalysis of chemical reactions. ${ }^{8-10}$ Hence, noteworthy effort has been made for the substitution of $\mathrm{Al}$ and/or $\mathrm{P}$ by other

\footnotetext{
*For correspondence
}

elements to generate negatively charged frameworks ${ }^{11}$ as well as Brönsted acid sites. The present study involves the synthesis of large pore $\mathrm{AlPO}_{4}-5$ molecular sieves substituted with $\mathrm{Mg}, \mathrm{Mn}$ and $\mathrm{Zn}$ and their catalytic activity towards vapor phase isopropylation of benzene with 2-propanol.

\section{Experimental}

\subsection{Materials}

Aluminum isopropoxide (Lancaster, 99\%), orthophosphoric acid (Qualigens, $85 \%$ ), $\mathrm{Mg}\left(\mathrm{CH}_{3} \mathrm{COO}\right)_{2}$. $4 \mathrm{H}_{2} \mathrm{O}, \mathrm{Mn}\left(\mathrm{CH}_{3} \mathrm{COO}\right)_{2} .4 \mathrm{H}_{2} \mathrm{O}$ and $\mathrm{Zn}\left(\mathrm{CH}_{3} \mathrm{COO}\right)_{2} .2 \mathrm{H}_{2} \mathrm{O}$, and triethylamine (TEA) (all Merck, 99\%) were the chemicals used as such in the study without further purification.

2.2 Synthesis of $\mathrm{AlPO}_{4^{-}}$, MAPO-5, MnAPO-5 and ZAPO-5

Aluminum isopropoxide $(28.37 \mathrm{~g})$ was soaked in $30 \mathrm{ml}$ distilled water in a stainless steel autoclave (316 type) and kept for ageing for $24 \mathrm{~h}$. This was vigorously stirred for an hour and $1.49 \mathrm{~g}$ magnesium acetate, dissolved in $9.2 \mathrm{ml}$ phosphoric acid and 
$20 \mathrm{ml}$ distilled water, was added drop by drop. This was then stirred for $1 \mathrm{~h}$, after which $9.7 \mathrm{ml}$ of TEA was added and the stirring continued for another hour. The gel $\mathrm{pH}$ was found to be 4 . The autoclave was tightly closed and kept at $175^{\circ} \mathrm{C}$ under autogenous pressure for $22 \mathrm{~h}$. The $\mathrm{pH}$ after synthesis was 9.4. The solid product formed was washed several times with distilled water and dried in an air oven at $110^{\circ} \mathrm{C}$ for $12 \mathrm{~h}$. Half of the sample was calcined at $550^{\circ} \mathrm{C}$ for $8 \mathrm{~h}$ to remove the template present in the sample. $\mathrm{AlPO}_{4}-5$ was synthesised using the same procedure but without magnesium acetate. MnAPO-5 and ZAPO-5 were also synthesised using the same procedure, using $1.7 \mathrm{~g}$ of manganese acetate and $1.52 \mathrm{~g}$ of zinc acetate respectively. The molar and gel compositions are given in table 1.

\subsection{Characterisation}

$\mathrm{AlPO}_{4}-5$, MAPO-5, ZAPO-5 and MnAPO-5 were characterised by X-ray diffraction (XRD), MASNMR, ICP-MS, BET, $n$-butylamine-TPD and SEM measurements, in order to study the structure, acidity, chemical composition, surface area and phase purity. The XRD patterns were recorded on a Siemens D 500 diffractometer using $\mathrm{CuK} \alpha$ radiation in the scan range of $2 \theta=5$ to $50^{\circ}$ with a scan rate of $1^{\circ}$ per minute. The morphology of these molecular sieves was observed on a JEOL JSM 5600 LV SEM. The chemical analysis of these catalysts was performed by using an ICP-MS optima 4300 DV spectrometer. ${ }^{27} \mathrm{Al}$ and ${ }^{31} \mathrm{P}$ MAS-NMR were recorded with a DSX 300 NMR spectrometer at 78.20 and $121.48 \mathrm{MHz}$ respectively. Magic angle spinning speeds of $5 \mathrm{kHz}$ were used for ${ }^{27} \mathrm{Al}$ and ${ }^{31} \mathrm{P}$. BET surface area measurements were carried out in Micromeritics pulse chemisorb 2700 using nitrogen as adsorbent at $97 \mathrm{~K}$. Acidity measurements were determined by $n$-butylamine-TPD method using Seiko SSC 5200H thermal analysis system attached to a TG/DTA 220 module.
About $50 \mathrm{mg}$ of calcined catalyst in each run was activated at $500^{\circ} \mathrm{C}$ for $1 \mathrm{~h}$ in a flow of air and the system was then kept in vacuum $\left(\sim 10^{-4}\right.$ torr $)$ at the same temperature. The catalysts were cooled down to room temperature. The given amount of $n$-butylamine (n-BA) was adsorbed on the catalyst in vapour phase. The catalysts that adsorbed $n$-BA were pretreated in vacuum to remove the excess amine from the catalyst surface at room temperature. The thermal desorption measurements were then made and from the weight loss, the acidity was determined. The acidity values obtained by this method show good agreement with the calculated values obtained by chemical composition. The chemical compositions, surface area and acidity values of these catalysts are presented in table 1.

\subsection{Catalytic studies}

The reactor system was a fixed-bed, vertical, flow type reactor made of glass tube of $40 \mathrm{~cm}$ length and $2 \mathrm{~cm}$ i.d. The glass reactor was heated to the requisite temperature with the help of a tubular furnace controlled by a digital temperature controller cum indicator. About $1 \mathrm{~g}$ of the catalyst was placed in the middle of the reactor and supported on either side with a thin layer of quartz wool and ceramic beads. The reactants were fed into the reactor by a syringe infusion pump that could be operated at different flow rates. The reaction was carried out at atmospheric pressure. The products were passed through a water-cooled condenser attached to the end of the reactor. The liquid products collected for the first 15 min were discarded and only the products collected thereafter were analysed. This was done to ensure the attainment of steady state for the reaction over the catalyst and also to eliminate temperature fluctuations. After each run, the catalyst was regenerated by passing $\mathrm{CO}_{2}$-free, dry air through the reactor at $500^{\circ} \mathrm{C}$ for $6 \mathrm{~h}$ in order to remove the deposited

Table 1. Gel composition, chemical analysis, surface area and acidity of aluminophosphate-based molecular sieves.

\begin{tabular}{lllcc}
\hline Catalyst & \multicolumn{1}{c}{ Gel composition } & \multicolumn{1}{c}{ Molar composition } & $\begin{array}{c}\text { BET surface } \\
\text { area }\left(\mathrm{m}^{2} / \mathrm{g}\right)\end{array}$ & $\begin{array}{c}\text { Acidity } \\
(\mathrm{mmol} / \mathrm{g})\end{array}$ \\
\hline $\mathrm{AlPO}_{4}-5$ & $\mathrm{Al}_{2} \mathrm{O}_{3}: \mathrm{P}_{2} \mathrm{O}_{5}: \mathrm{TEA}: 40 \mathrm{H}_{2} \mathrm{O}$ & $\mathrm{Al}_{2} \mathrm{O}_{3}: \mathrm{P}_{2} \mathrm{O}_{5}$ & 203 & - \\
$\mathrm{MgPO}-5$ & $0 \cdot 1 \mathrm{MgO}: \mathrm{Al}_{2} \mathrm{O}_{3}: \mathrm{P}_{2} \mathrm{O}_{5}:$ TEA $: 40 \mathrm{H}_{2} \mathrm{O}$ & $0 \cdot 083 \mathrm{MgO}: 0 \cdot 917 \mathrm{Al}_{2} \mathrm{O}_{3}: \mathrm{P}_{2} \mathrm{O}_{5}$ & 224 & $0 \cdot 14$ \\
$\mathrm{ZnPO}-5$ & $0 \cdot 1 \mathrm{ZnO}: \mathrm{Al}_{2} \mathrm{O}_{3}: \mathrm{P}_{2} \mathrm{O}_{5}: \mathrm{TEA}: 40 \mathrm{H}_{2} \mathrm{O}$ & $0 \cdot 074 \mathrm{ZnO}: 0 \cdot 926 \mathrm{Al}_{2} \mathrm{O}_{3}: \mathrm{P}_{2} \mathrm{O}_{5}$ & 252 & $0 \cdot 28$ \\
$\mathrm{MnAPO}-5$ & $0 \cdot 1 \mathrm{MnO}: \mathrm{Al}_{2} \mathrm{O}_{3}: \mathrm{P}_{2} \mathrm{O}_{5}: \mathrm{TEA}: 40 \mathrm{H}_{2} \mathrm{O}$ & $0 \cdot 087 \mathrm{MnO}: 0 \cdot 913 \mathrm{Al}_{2} \mathrm{O}_{3}: \mathrm{P}_{2} \mathrm{O}_{5}$ & 260 & $0 \cdot 34$ \\
\hline
\end{tabular}


coke. The products were identified using a Shimadzu GCMS-QP5000 and analysed using Shimadzu gas chromatograph using CP-Sil 19 column.

\section{Results and discussion}

\subsection{Structure}

Figure 1 shows the XRD patterns of $\mathrm{AlPO}_{4}-5$, MAPO-5, ZAPO-5 and MnAPO-5. The materials are crystalline and do not contain detectable impure phases. XRD also shows that the structure is stable even after calcination at $550^{\circ} \mathrm{C}$ for $8 \mathrm{~h}$ in a stream of dry air. MAS-NMR indicates the isomorphous substitution by $\mathrm{Mg}, \mathrm{Zn}$ and $\mathrm{Mn}$ in the framework of aluminophosphate molecular sieves. Figures 2 and 3 illustrate the ${ }^{27} \mathrm{Al}$ and ${ }^{31} \mathrm{P}$ NMR of $\mathrm{AlPO}_{4}-5$, MAPO5, ZAPO-5 and MnAPO-5 respectively. Strong signals are observed at $35.85 \mathrm{ppm}\left(\mathrm{AlPO}_{4}-5\right), 37.51 \mathrm{ppm}$ (MAPO-5), $38.83 \mathrm{ppm}$ (ZAPO-5), and $34.46 \mathrm{ppm}$ (MnAPO-5) for aluminum and at $-26.68 \mathrm{ppm}$ $\left(\mathrm{AlPO}_{4}-5\right), \quad-28.39 \mathrm{ppm}$ (MAPO-5), $-29.67 \mathrm{ppm}$ (ZAPO-5) and $-25.92 \mathrm{ppm}$ (MnAPO-5) for phosphorus. ${ }^{9,12}$ The spinning side bands in the ${ }^{31} \mathrm{P}$ resonance indicate $\mathrm{Mg}, \mathrm{Zn}$ and $\mathrm{Mn}$ incorporated in the framework. The ${ }^{31} \mathrm{P}$ MAS-NMR spectra of MnAPO5 show characteristic side bands, arising from strong dipolar interactions ${ }^{13}$ with paramagnetic manganese. This spectrum is the result of contributions from

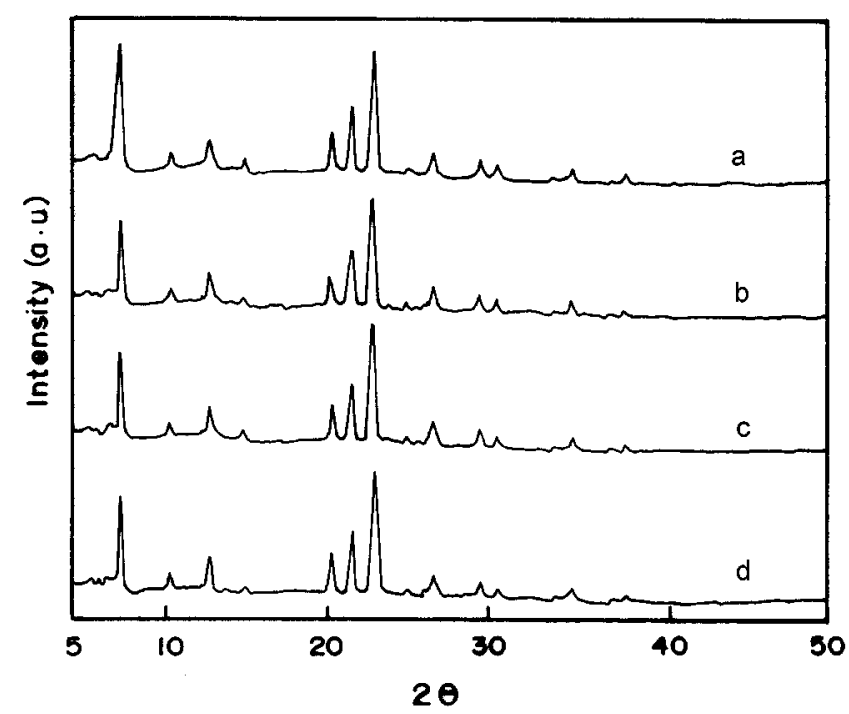

Figure 1. X-ray diffraction patterns of the calcined samples. (a) AlPO-5, (b) MAPO-5, (c) ZAPO-5 and (d) MnAPO-5. both dipolar interactions and chemical shift anisotropy. If manganese is substituting for framework aluminum, one would expect more than a single resonance in the ${ }^{31} \mathrm{P}$ spectrum. Table 1 presents the BET surface area of all these catalysts. The catalysts have surface areas between 203 and $260 \mathrm{~m}^{2} / \mathrm{g}$. The acidity values presented in table 1 show that MnAPO-5 is more acidic than ZAPO-5 and MAPO5 , indicating higher substitution by $\mathrm{Mn}$ in MnAPO-5 than by $\mathrm{Zn}$ in ZAPO-5 and by Mg in MAPO-5. Table 1 shows the chemical composition of all the catalysts. The chemical composition indicates the following order of metal substitution: ZAPO-5 < MAPO-5 < MnAPO-5. The acidity order of the catalyst is: MAPO- 5 ZAPO- $5<$ MnAPO-5. The orders for acidity and chemical composition are different, this may be due to removal of framework Mg during calcination which remains in the solid as extra framework species. The scanning electron micrographs of $\mathrm{AlPO}_{4}-5$, MAPO-5, ZAPO-5 and MnAPO5 are shown in figure 4 . The catalysts appear as

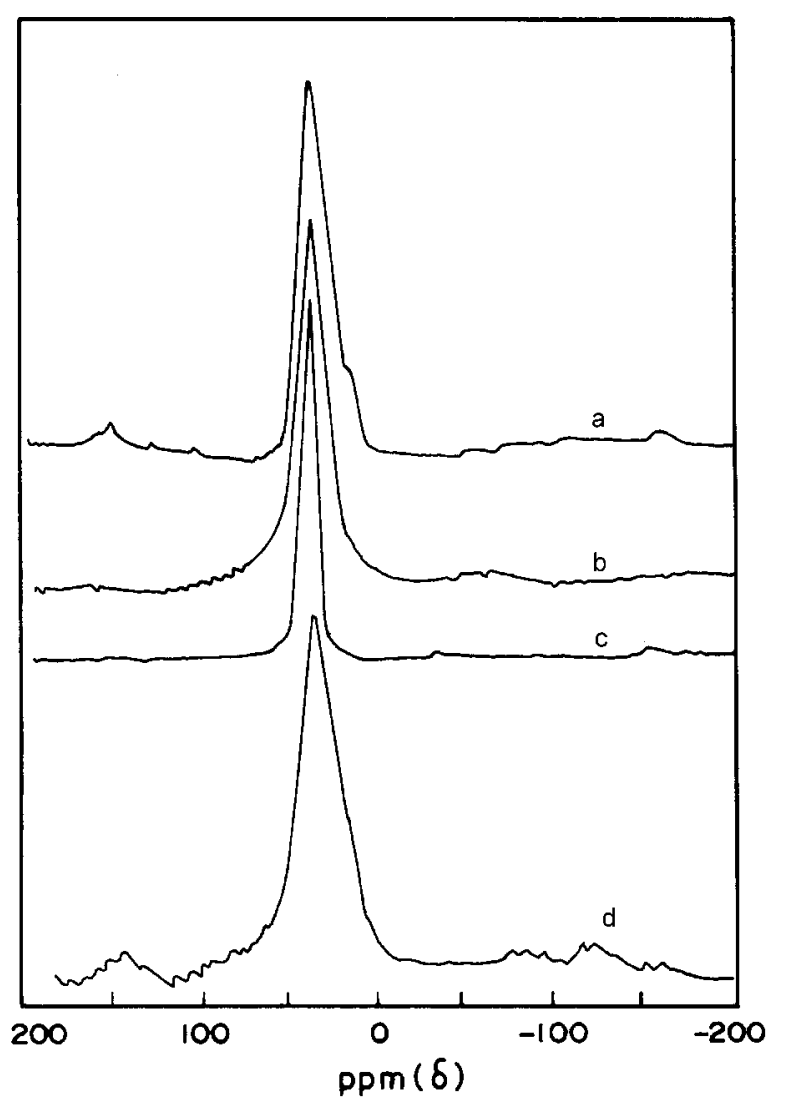

Figure 2. Solid-state ${ }^{27} \mathrm{Al}$ NMR spectra of the calcined samples. (a) AlPO-5, (b) MAPO-5, (c) ZAPO-5 and (d) MnAPO-5. 


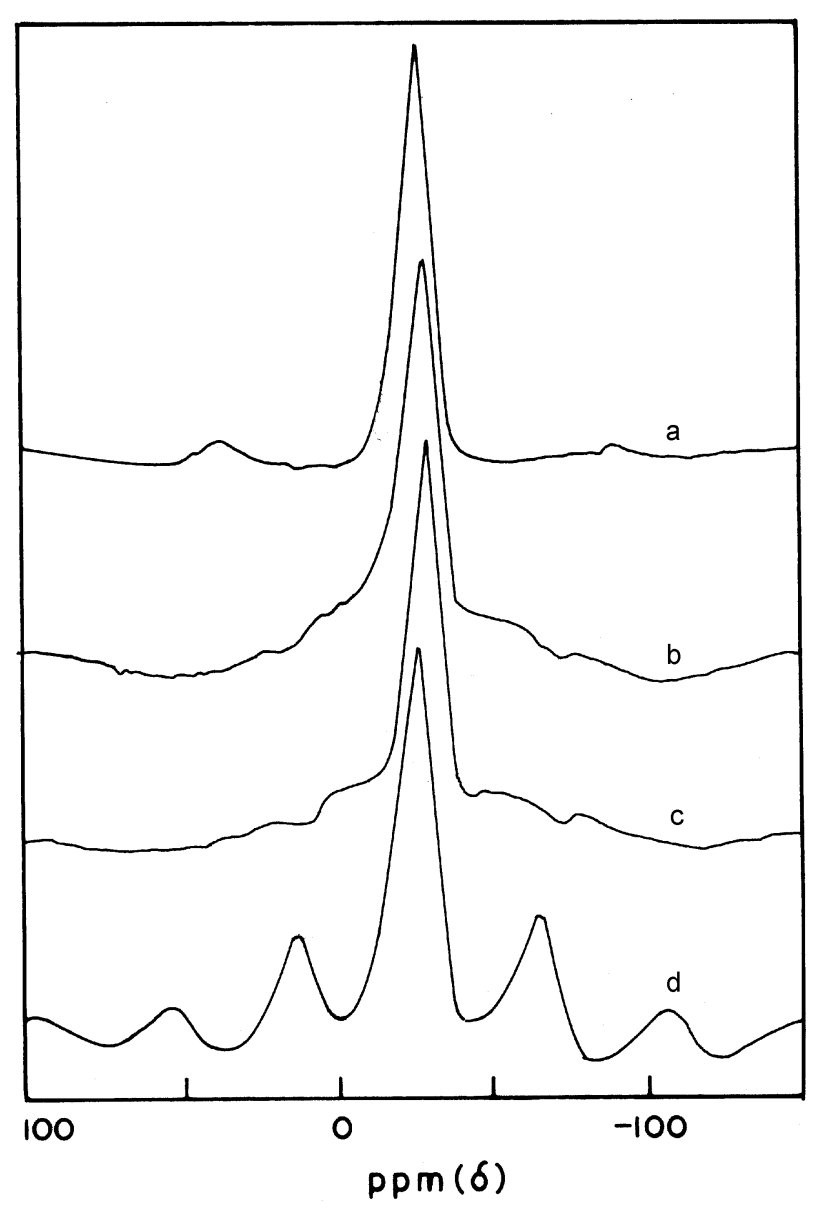

Figure 3. Solid-state ${ }^{31} \mathrm{P}$ NMR spectra of the calcined samples. (a) AlPO-5, (b) MAPO-5, (c) ZAPO-5 and (d) MnAPO-5.

polycrystalline aggregates of spherical morphology. Each tiny crystal is of platy type with definite edges and sharp corners. The morphology of the catalysts $\mathrm{AlPO}_{4}-5$, MAPO-5, ZAPO-5 and MnAPO-5 appears to be the same, indicating phase purity.

\subsection{Isopropylation of benzene}

Isopropylation of benzene with 2-propanol over $\mathrm{AlPO}_{4}-5$, MAPO-5, ZAPO-5 and MnAPO-5 was studied at $250,300,350$ and $400^{\circ} \mathrm{C}$, with feed ratio $1: 3$ for benzene :2-propanol, and WHSV $=2 \mathrm{~h}^{-1}$. The plots of conversion vs temperature for all the catalysts are shown in figure 5 . The products of the reaction were found to be cumene, $p$-DIPB, and $m$ DIPB. The plot of product yield vs temperature for MnAPO-5 is shown in figure 6.

\subsection{Effect of temperature}

Figure 5 shows a linear response of conversion with increase in temperature over $\mathrm{AlPO}_{4}-5$. As the isopropylation of benzene with 2-propanol requires prior formation of isopropyl cation, the reaction requires the presence of Brönsted acid sites on the catalyst surface. Since $\mathrm{AlPO}_{4}-5$ possesses a neutral framework, the acid sites required to adsorb and yield isopropyl cations have to be derived from the defective $-\mathrm{OH}$ groups of the catalyst on its surface. As the conversion is sufficiently significant, $0 \cdot 4$ $3 \%$, the catalyst is expected to have a significant number of defective sites. As isomorphic substitution of $\mathrm{M}^{2+}$ ion in the framework would produce a higher density of acid sites, the reaction was also studied over MAPO-5, ZAPO-5 and MnAPO-5. These catalysts show higher conversion than $\mathrm{AlPO}_{4}{ }^{-}$ 5. The order of benzene conversion is found to be $\mathrm{AlPO}_{4}-5<\mathrm{MAPO}-5<\mathrm{ZAPO}-5<\mathrm{MnAPO}-5$. This order of conversion reproduces the order of acidity. The benzene conversion over $\mathrm{AlPO}_{4}-5$ is nearly zero at $250^{\circ} \mathrm{C}$ indicating the absence of isopropyl cation formation. The increase in conversion over MAPO5, ZAPO-5 and MnAPO-5 at $300^{\circ} \mathrm{C}$, viz., 3-6\%, suggests sufficient concentration of alcohols in the pores. Among the catalysts MnAPO-5 gives higher conversion than $\mathrm{AlPO}_{4}-5$, MAPO-5 and ZAPO-5. The effect of temperature on product yield was examined over MnAPO-5 and the results are illustrated in figure 6 . The selectivity to cumene over MnAPO-5 increases with temperature up to $350^{\circ} \mathrm{C}$, and remaines unchanged thereafter. The yield of $p$ DIPB and $m$-DIPB increases with temperature up to $350^{\circ} \mathrm{C}$ but at $400^{\circ} \mathrm{C}$ a decrease is observed. Other products like toluene, ethylbenzene and $n$-propylbenzene are also formed but up to a limit of $<1 \%$. Formation of cumene with high selectivity might be due to its free diffusion without steric hindrance through the pores. The lower selectivity towards $p$-DIPB and $m$-DIPB might be due to steric hindrance to diffusion. Formation of nearly $12 \%$ cumene, $7 \%$ DIPB and only $0.5 \%$ of $n$-propylbenzene yield at $350^{\circ} \mathrm{C}$ is an important observation to note in this study. Although ZAPO-5 gives higher conversion next to MnAPO-5, the yield patterns obtained with ZAPO-5 indicate a similar selectivity to DIPB and hence the results obtained with MnAPO-5 alone are discussed. The selectivity to $m$-DIPB is not as high as $p$-DIPB, and this might be due to (i) steric hindrance for meta substitution, (ii) greater 
a

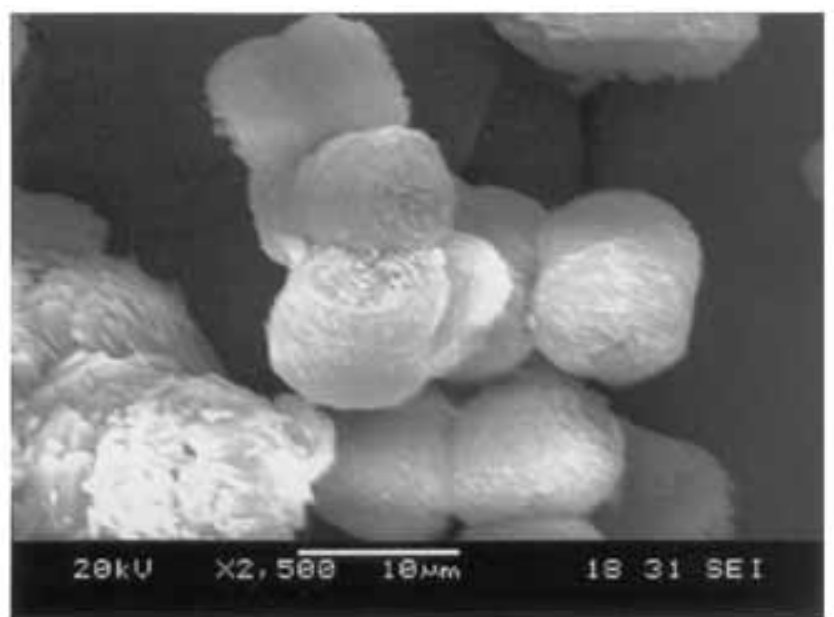

C

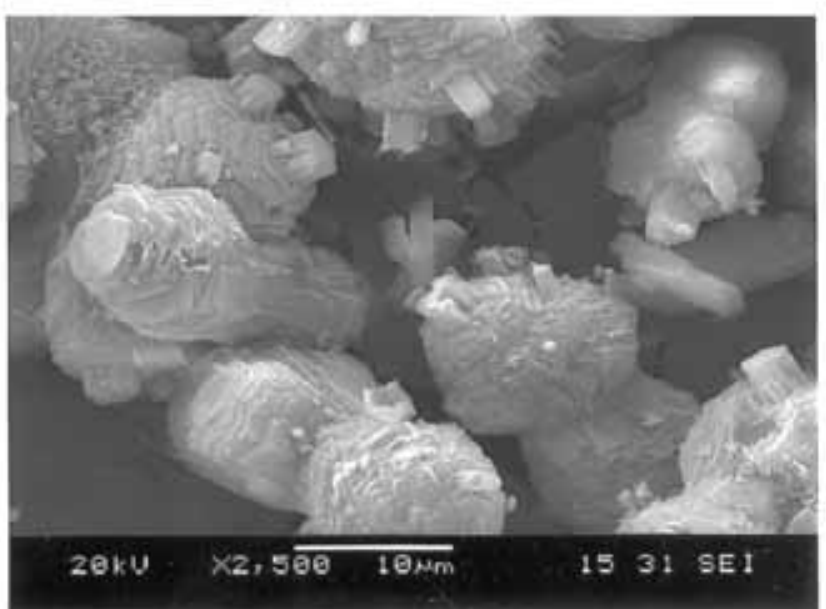

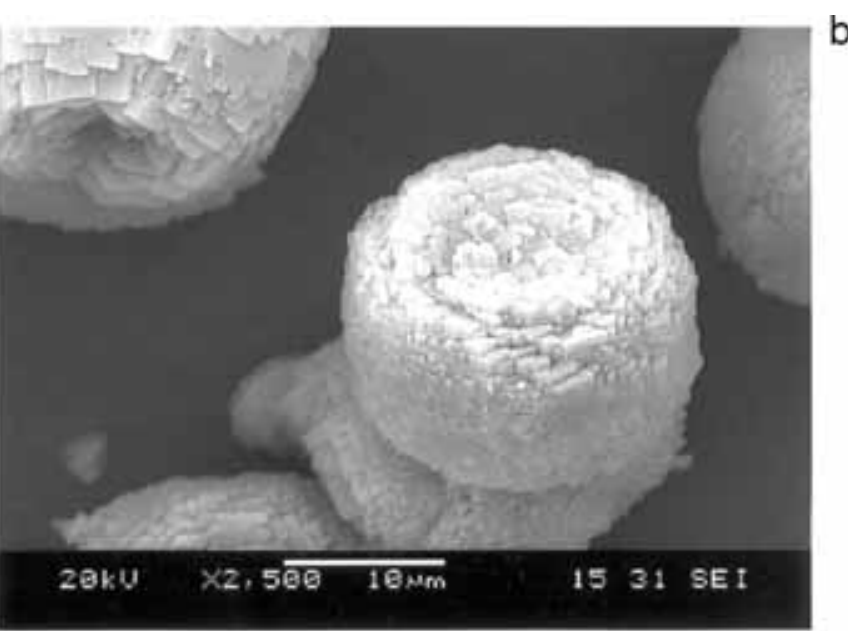

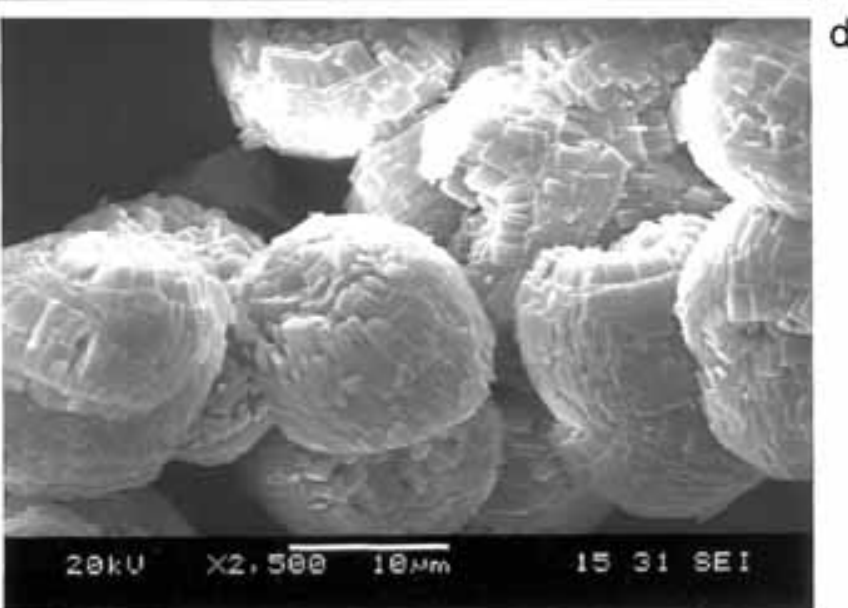

Figure 4. SEM photographs of the calcined samples. (a) AlPO-5, (b) MAPO-5, (c) ZAPO-5 and (d) MnAPO-5.

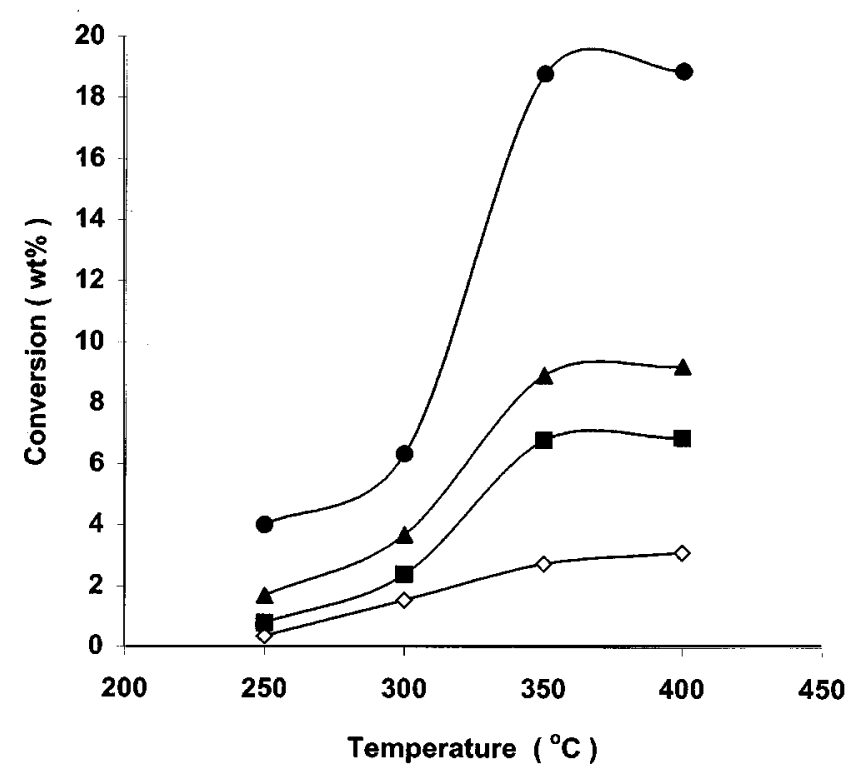

Figure 5. Effect of temperature on benzene conversion over $\diamond$ AlPO-5, MAPO-5, $\triangle \mathrm{ZAPO}-5$ and $\bullet \mathrm{MnAPO}-$ 5 ; WHSV $=2 \mathrm{~h}^{-1}$; benzene $: 2$-propanol $=1: 3$.

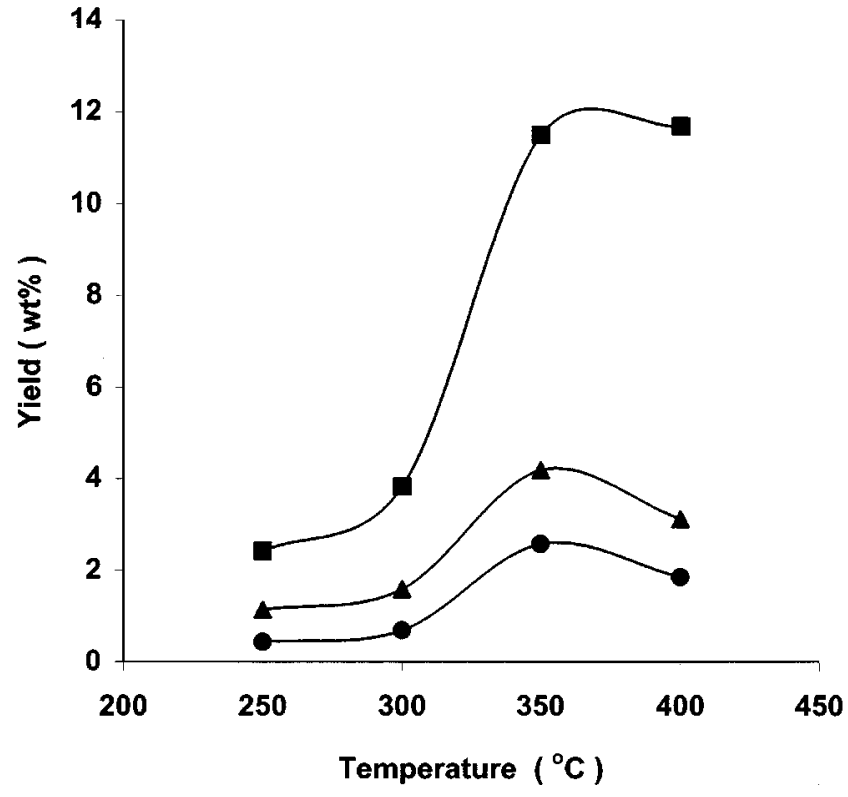

Figure 6. Effect of temperature on product yield over MnAPO-5. Cumene, $\boldsymbol{\Delta} p$-DIPB and $m$-DIPB; $\mathrm{WHSV}=2 \mathrm{~h}^{-1}$; benzene $: 2$-propanol $=1: 3$. 


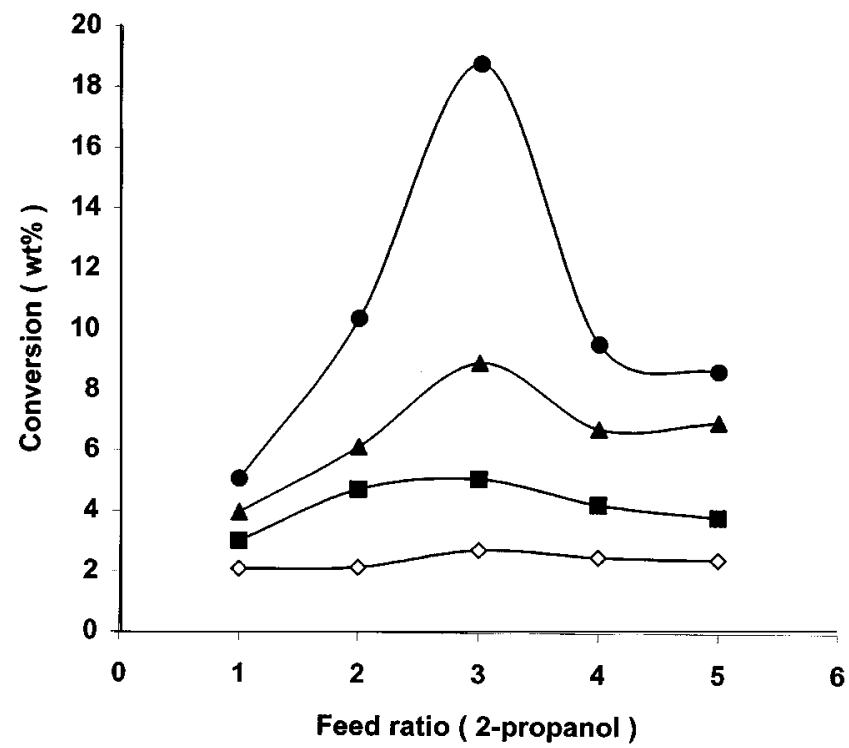

Figure 7. Effect of feed ratio on benzene conversion

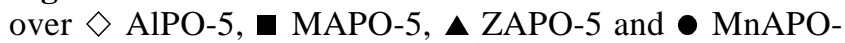
5; temp. $=350^{\circ} \mathrm{C}$; WHSV $=2 \mathrm{~h}^{-1}$.

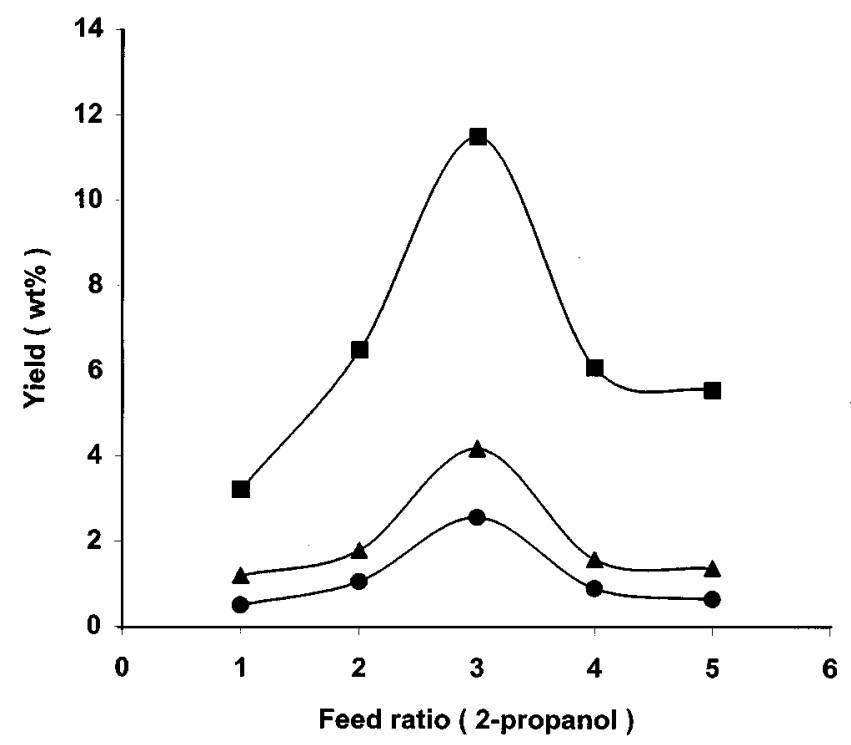

Figure 8. Effect of feed ratio on product yield over MnAPO-5. (Feed ratio of 2-propanol varied from 1 to 5 parts keeping benzene as 1 part.) $\square$ Cumene, $\boldsymbol{\Delta} p$-DIPB, and $m$-DIPB; temp. $=350^{\circ} \mathrm{C} ; \mathrm{WHSV}=2 \mathrm{~h}^{-1}$.

diffusion coefficient for $p$-DIPB than for $m$-DIPB, and (iii) $p$-directing influence of the isopropyl group in cumene.

\subsection{Effect of feed ratio}

The influence of feed ratio on conversion over $\mathrm{AlPO}_{4}-5$, MAPO-5, ZAPO-5 and MnAPO-5 was

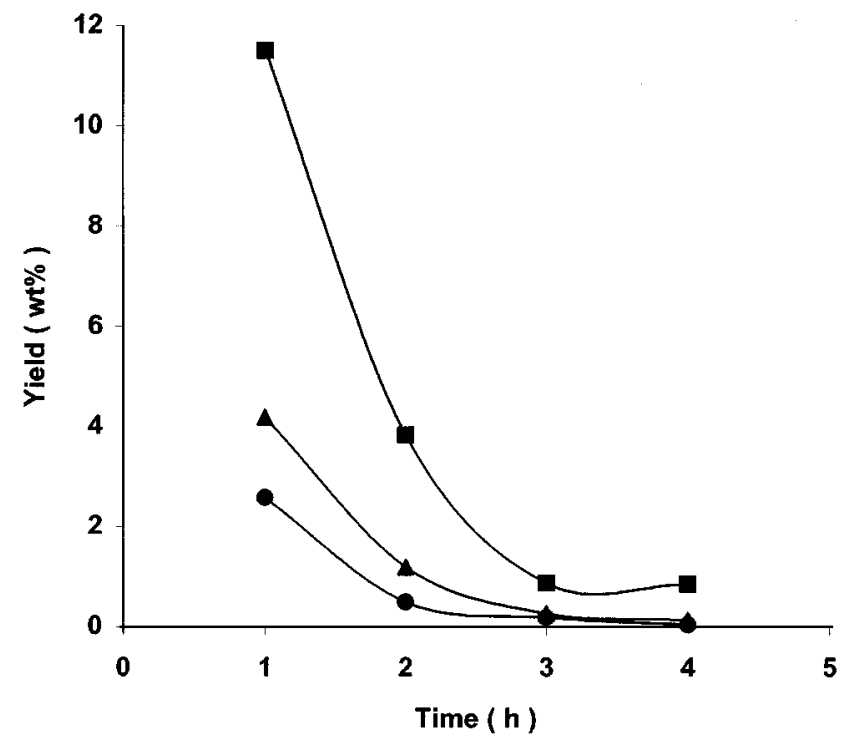

Figure 9. Effect of time-on-stream on product yield over MnAPO-5. Cumene, $\boldsymbol{\Delta} p$-DIPB, and $-m$-DIPB; temp. $=350^{\circ} \mathrm{C} ; \quad$ benzene $: 2$-propanol $=1: 3 ; \quad$ WHSV $=$ $2 \mathrm{~h}^{-1}$.

studied at $350^{\circ} \mathrm{C}$ with feed ratios of benzene: 2-propanol; $1: 1,1: 2,1: 3,1: 4$ and $1: 5$ with WHSV = $2 \mathrm{~h}^{-1}$. The results are presented in figure 7. The plot indicates a nonlinear response over MnAPO-5 and ZAPO-5. Over $\mathrm{AlPO}_{4}-5$ and MAPO-5 the conversion remains unchanged with feed ratios. The increase in conversion over the catalysts up to a feed ratio of $1: 3$ should be due to an increase in the formation of isopropyl cation on the catalyst surface but a decrease in conversion thereafter is possibly due to a decrease in availability of benzene at the active site due to slower diffusion. The conversion over MnAPO-5 is high at all the feed ratios compared to other catalysts. The difference in conversion is greater than that expected on the basis of the difference in acidity. Figure 8 illustrates the influence of feed ratio on yield of products over MnAPO-5. There is an increase in cumene and DIPB selectivity up to $1: 3$. Cumene selectivity is higher at a feed ratio of $1: 3$ as there would be a lower probability for DIPB.

\subsection{Effect of time-on-stream}

Figure 9 illustrates the effect of time on stream on the yield of products. There is a decrease in conversion with increase in stream due to blocking of active sites by coke. The rapid decrease in the activity 
of the catalysts with time on stream might be due to the microporous nature which causes much diffusional constraint for the primary products, facilitating the formation of multialkylated products with the precursors of coke. A decrease in yield is observed for all the products up to three hours but then there is a slight increase in selectivity for cumene as there is coke formation with time on stream at the end of the third hour leading to a partial decrease in the pore size.

\section{Conclusion}

The vapour phase reaction of isopropylation of benzene with 2-propanol over $\mathrm{AlPO}_{4}-5$ shows conversion of about $3 \%$ at $350{ }^{\circ} \mathrm{C}$. The activity of this catalyst is attributed to defect sites containing $-\mathrm{OH}$ group. The major bi-product was DIPB. MAPO-5, ZAPO-5 and MnAPO-5 give higher conversion than $\mathrm{AlPO}_{4}-5$ due to isomorphous substitution of metal in the framework of the catalyst. Among the catalysts, MnAPO-5 gives higher conversion and yield of cumene, due to the higher acidity of MnAPO-5, a role for the unpaired electrons in the $d$-subshell of $\mathrm{Mn}$ is an interesting possibility. An interesting observation in this study is the increase in the selectivity to cumene with increase in stream. It may be due to a gradual reduction in the pore size of the catalyst by coke deposition.

\section{Acknowledgements}

We thank Dr M Palanichamy of the Anna University for helpful discussions during the preparation of this manuscript and Dr T Balakrishnan for encouragement.

\section{References}

1. Pujado P R, Salazar J R and Berger C V 1976 Hydrocarbon Process. 5591

2. Yen Y C 1977 Stanford Res. Inst. PEP B22

3. Miki H 1982 U.S. Patent 4,347,393

4. Goelzer A R, Ram S, Hernandez A, Chin A A, Harandi M N and Smith C M 1993 NPRA Annual Meeting AM-93-19

5. Chen J 1993 Worldwide solid acid process conference, Houston, Texas; Fong S W 1994 PEP Rev. 923

6. Pradhan A R, Kotasthane A N and Rao B S 1991 Appl. Catal. A72 311

7. Pradhan A R and Rao B S 1991 J. Catal. 13279

8. Elangovan S P, Krishnasamy V and Murugesan V 1995 Hungarian J. Ind. Chem. 23119

9. Elangovan S P, Krishnasamy V and Murugesan V 1996 Catal. Lett. 36271

10. Elangovan S P, Kannan C, Arabindoo B and Murugesan V 1998 Appl. Catal. A174 213

11. Lok B M, Messina C A, Patton R L, Gajek R T, Cannan T R and Flanigen E M 1984 J. Am. Chem. Soc. 1066092

12. Blackwell C S and Patton R L 1984 J. Phys. Chem. 886135

13. Montes C, Davis M E, Murray B and Narayana M 1990 J. Phys. Chem. 946425 